\title{
Fatores que afetam a germinação de sementes e emergência de plântulas de arruda (Ruta graveolens L.)
}

\author{
YAMASHITA, O.M. ${ }^{1}$; FERNANDES NETO, E. ${ }^{1}$; CAMPOS, O.R. ${ }^{1}$; GUIMARÃES, S.C. ${ }^{2}$ \\ Universidade do Estado de Mato Grosso -I UNEMAT, Departamento de Agronomia, Caixa Postal 324, 78580-000, \\ Alta Floresta - MT *yama@unemat.br. ${ }^{2}$ Universidade Federal de Mato Grosso - UFMT, Faculdade de Agronomia e \\ Medicina Veterinária, Av. Fernando Corrêa da Costa s/n, 78060-000, Cuiabá- MT.
}

\begin{abstract}
RESUMO: Ruta graveolens L., também conhecida com arruda, é planta originária do sul da Europa, cultivada no Brasil e em outros países como planta medicinal, muito utilizada em rituais religiosos. Tendo em vista que a germinação constitui um fator primordial para que a semente possa gerar uma planta vigorosa e comalto potencial produtivo, o presente trabalho teve como objetivo avaliar a resposta germinativa de sementes para arruda sob condições de temperatura, luminosidade, estresse hídrico e salino e emergência de plântulas em diferentes profundidades de semeadura. Sementes de Ruta graveolens são indiferentes à luz, germinando melhor em temperatura constante de $25^{\circ} \mathrm{C}$ ou alterna $\left(20-30^{\circ} \mathrm{C}\right)$. Os potenciais osmóticos induzidos por manitol a partir de $-0,4 \mathrm{MPa}$ e por $\mathrm{NaCl}$ a partir de $-0,8 \mathrm{MPa}$ influenciam negativamente o processo germinativo. Maiores percentuais de plântulas são obtidas quando a espécie é semeada na superfície do substrato.
\end{abstract}

Palavras-chave: luz, temperatura, potencial osmótico, estresse salino, profundidade de semeadura

\begin{abstract}
Factors affecting seed germination and seedling emergence in rue (Ruta graveolens L.). Ruta graveolens L., also known as rue, is from the south of Europe, cultivated in Brazil and other countries as a medicinal plant greatly used in religious rituals. Since germination is essential for the seed to generate a vigorous plant of high productive potential, this work aimed to evaluate the germinative response of rue seeds under different temperatures, luminosity conditions, and water and salt stress, besides seedling emergence at different sowing depths. Ruta graveolens $\mathrm{L}$. seeds are indifferent to light, better germinating at constant temperature of $25^{\circ} \mathrm{C}$ or alternated temperature $\left(20-30^{\circ} \mathrm{C}\right)$. The osmotic potentials induced by mannitol from $0.4 \mathrm{MPa}$ and by $\mathrm{NaCl}$ from-0.8MPa negatively influenced the germination process. Higher seedling percentages are obtained when the species is sown on the substratum surface.
\end{abstract}

Key words: light, temperature, osmotic potential, salt stress, sowing depth

\section{INTRODUÇÃO}

Cerca de 100.000 espécies vegetais existentes no Brasil podem ter alguma propriedade terapêutica útil à população, mas nem $1 \%$ dessas espécies compotencial foi motivo de estudo (Martins et al., 2003).

A arruda (Ruta graveolens L.), também conhecida como arruda-fedorenta, ruta-de-cheiro-forte, arruda-doméstica e arruda-dos-jardins é uma espécie perene pertencente à família Rutaceae (Lorenzi \& Matos, 2002) largamente utilizada como recurso medicinal pela população local em todo o Brasil
(Souza et al., 2007). Forma arbustos de ramos e folhas de coloração verde-azulada, apresentando flores pequenas e amarelas. Na medicina popular, a espécie é tida como uma planta mágica, utilizada pelo homem desde muito tempo em rituais de proteção, principalmente em crianças contra o mal olhado, desordens menstruais, inflamações na pele, câimbras, dor de ouvido e dente. Ensaios farmacológicos comprovaram seu efeito como antihelmíntica, febrífuga, emenagoga e abortiva (Lorenż \& Matos, 2002). 
O processo germinativo na semente é caracterizado pela reativação do metabolismo paralisado após a maturidade fisiológica e pode ser afetado por fatores internos, externos ou ambientais (Carvalho \& Nakagawa, 2000). Dentre os fatores ambientais, considera-se água, oxigênio e temperatura como componentes vitais que determinam a intensidade e a velocidade de germinação da espécie (Marcos Filho, 1986; Bewley \& Black, 1994). Além disso, condições de luminosidade e mecanismos de adaptação à salinidade do substrato são fatores determinantes para a germinabilidade das sementes (Fanti \& Perez, 1998).

A capacidade de germinação constitui um dos pontos mais críticos para determinar o sucesso no estabelecimento de um estande adequado de plantas, por isso, estudos sobre o efeito de luminosidade, temperatura, água, salinidade são essenciais para se entender os aspectos ecológicos e fisiológicos que envolvem o processo (Labouriau, 1983). A habilidade da semente em germinar sob amplas condições ambientais, onde esta foi semeada, determina seu vigor e conseqüentemente a sua capacidade competitiva (Perez \& Tambelini, 1995).

Opresente trabalho teve como objetivo avaliar os aspectos germinativos de sementes de arruda sob diferentes condições de temperatura, luminosidade, estresse hídrico e salino, além de avaliação da emergência da espécie à profundidade de semeadura.

\section{MATERIALE MÉTODO}

Os experimentos foram conduzidos no Laboratório de Sementes da Universidade do Estado de Mato Grosso (UNEMAT), Campus Universitário de Alta Floresta, MT no período compreendido entre fevereiro e abril de 2008.

Para o estudo dos aspectos germinativos das sementes e de emergência das plântulas de arruda, foram realizados quatro ensaios com sementes adquiridas junto ao comércio local, analisadas em janeiro de 2008.

Para todos os ensaios, foi utilizado o delineamento experimental inteiramente casualizado com 4 repetições, sendo que para os testes de germinação, cada parcela foi representada por uma caixa transparente (gerbox $11,0 \times 11,0 \times 3,5 \mathrm{~cm}$ ) com 50 sementes colocadas sobre duas folhas de papel mata-borrão, umedecidas coma solução própria, na quantidade de 2,5 vezes a massa do substrato seco (Brasil, 1992). As sementes foram consideradas germinadas quando a raiz primária apresentava comprimento igual ou superior a $1,0 \mathrm{~mm}$. 0 reumedecimento do substrato feito no sétimo e décimo quinto dia após a montagem dos experimentos, para todos os tratamentos.

\section{Temperatura e luminosidade}

Para o ensaio de temperatura, as sementes foram submetidas a esquema fatorial $3 \times 2$, ou seja, três condições de regimes térmicos $\left(25\right.$ e $30^{\circ} \mathrm{C}$ constantes e ambiente de laboratório); e duas condições de luminosidade (ausência e presença de luz). Para a condição de ausência de luz, as sementes foram colocadas em caixas gerbox e envolvidas com duas camadas de alumínio flexível. Todas as caixas foram envolvidas em filme plástico transparente e distribuídas aleatoriamente dentro de câmaras de germinação tipo BOD (regulada para 12 horas de luz), para tratamentos com temperaturas constantes, ou sobre bancada no laboratório (temperatura variável entre 20 e $29^{\circ} \mathrm{C}$ ).

As avaliações eram feitas diariamente para os tratamentos em presença de luz, durante 23 dias, sempre no mesmo horário, retirando-se as sementes germinadas. No décimo quinto dia, as caixas no escuro foramabertas, sendo contadas e retiradas as sementes germinadas. As sementes foram posteriormente colocadas em caixas transparentes sobre duas folhas de papel mata-borrão umedecido como citado anteriormente, e mantidas nos mesmos ambientes de germinação por mais oito dias. $\mathrm{O}$ substrato do tratamento em condições ausência de luz foi hidratado no sétimo dia em câmara escura sob luz verde. Com base nesses dados, foram confeccionadas tabelas com a germinabilidade acumulada até 0 15o e 23ㅇdias para todos os tratamentos, além do índice de velocidade de germinação (Maguire, 1962).

\section{Estresse hídrico}

Para o teste de estresse hídrico, foram preparadas soluções de manitol (PM 182,17 g) nas concentrações de 0,$0 ;-0,2 ;-0,4 ;-0,6 ;-0,8$ e -1,0MPa. $\mathrm{O}$ cálculo da quantidade de manitol para cada concentração foi obtido utilizando-se a fórmula de Van't Hoff, citado por Nassif \& Perezet al. (1997), ou seja:

$$
g=(P \vee M) \cdot(R T)^{-1}
$$

onde: g: massa de manitol (g); P: pressão osmótica (atm); V: volume (L); M: peso molecular do manitol; R: 0,08205 atm K$^{-1}$ mol-1-1 $^{-1}$ : temperatura (K)

As caixas foram dispostas aleatoriamente em câmaras de germinação tipo BOD com temperatura constante de $25^{\circ} \mathrm{C}$ e fotoperíodo de 12 h. Aadição solução hidratante do substrato foi feito no sétimo e décimo quinto dias após a montagem dos experimentos, substituindo-se os papéis por outros previamente umedecidos comas respectivas soluções.

As avaliações foram diárias, onde as sementes germinadas eramcontadas e retiradas. As sementes foram consideradas germinadas quando a 
raiz primária apresentava comprimento igual ou superior a 1,0 mm. Com base nesses dados, foram confeccionados gráficos de germinabilidade acumulada aos 20 dias e índice de velocidade de germinação (Maguire, 1962).

\section{Estresse salino}

Para indução do estresse salino foram utilizadas soluções com diferentes concentrações de $\mathrm{NaCl}$ (PM 58,44 g), obtidas a partir da fórmula de Van't Hoff, de acordo com Nassif \& Perez(1997), ou seja:

$$
\Psi_{0 s}=\text { - i C R T }
$$

onde: $\Psi$ os $=$ potencial osmótico $(\mathrm{atm})$; i: coeficiente isotônico de $\mathrm{NaCl}(1,8) ; \mathrm{R}: 0,0831$ (kg bar $\mathrm{K}^{-1} \mathrm{~mol}^{-1}$ ); T: temperatura $(\mathrm{K})$; C: concentração (mol do soluto) $\left(\mathrm{kg} \mathrm{H}_{2} \mathrm{O}\right)^{-1}$

Após a disposição das sementes sobre o substrato, dentro de caixas transparentes, estas foram distribuídas aleatoriamente em câmaras tipo $\mathrm{BOD}$ regulada para $25^{\circ} \mathrm{C}$ e $12 \mathrm{~h}$ de fotoperíodo. $\mathrm{O}$ substrato foi hidratado de acordo com o descrito para ensaio de estresse hídrico.

As avaliações eramrealizadas diariamente, contando e retirando-se as sementes germinadas. Considerou-se germinada a semente comraiz primária com comprimento igual ou superior a $1,0 \mathrm{~mm}$.

Com base nos dados coletados, foram confeccionados gráficos de germinabilidade acumulada aos 20 dias e índice de velocidade de germinação (Maguire, 1962).

\section{Profundidade de semeadura}

Para o teste de profundidade, foi montado ensaio em esquema fatorial $3 \times 5$, sendo três texturas de substrato e cinco profundidades de semeadura. Foram utilizados os seguintes substratos: solo argiloso, areia e solo/areia (em proporções equivalentes), nas profundidades de semeadura de 0,$0 ; 0,5 ; 1,0 ; 2,0$ e $4,0 \mathrm{~cm}$. Oexperimento foi conduzido em condições de ambiente coberto da insolação direta de luminosidade, em vasos plásticos com capacidade de 1,0 L. Foram colocadas 25 sementes por vaso nas suas respectivas profundidades. $O$ fornecimento de água era feito por sub-irrigação. A avaliação foi feita após 20 dias da semeadura, sendo contado o número de plântulas emersas por unidade experimental.

Os valores em porcentagem de germinação foram previamente transformados em arco seno [raiz $(\% / 100)]$. Os dados foram submetidos à análise de variância e as médias comparadas pelo teste de Tukey a $5 \%$ de probabilidade, utilizando o programa estatístico SISVAR 4.3 (Ferreira, 2003).

\section{RESULTADO E DISCUSSÃO}

\section{Temperatura e luminosidade}

Foram observadas diferenças significativas para o fator temperatura $(p<0,01)$ e também para a interação entre temperatura e luminosidade $(p<0,05)$ tanto na contagem realizada aos 15 como aos 23 dias (Tabela 1).

Não foi observada diferença de germinabilidade entre as condições de luminosidade a $25^{\circ} \mathrm{C}$ e em ambiente, tanto na contagem aos 15 como aos 23 dias, mostrando que estas condições propiciaram maiores respostas germinativas da espécie. Menores percentuais de germinação foram obtidos a $30^{\circ} \mathrm{C}$, tanto na presença como na ausência de luz. Esses resultados concordam com Stefanello et al. (2006b), que observaram redução da germinabilidade das sementes de Pimpinella anisum a $30^{\circ} \mathrm{C}$, se comparado comtemperaturas inferiores/ alternas.

A espécie apresentou comportamento indiferente à luz, em temperaturas ótimas $\left(25^{\circ} \mathrm{C}\right.$ e em ambiente). Os resultados concordam com os obtidos por alguns autores que classificam espécies como plantas insensíveis à luz, visto que estas produzemsementes que germinam tanto na presença

TABELA 1. Germinabilidade de sementes de Ruta graveolens, após 15 e 23 dias, emfunção da temperatura de incubação e tratamento prévio de escuro (15 dias). Alta Floresta, MT. 2008

\begin{tabular}{|c|c|c|c|c|c|c|}
\hline \multirow{3}{*}{ Luminosidade } & \multicolumn{6}{|c|}{ Temperatura } \\
\hline & $25^{\circ} \mathrm{C}$ & $30^{\circ} \mathrm{C}$ & Ambiente ${ }^{1}$ & $25^{\circ} \mathrm{C}$ & $30^{\circ} \mathrm{C}$ & Ambiente \\
\hline & \multicolumn{3}{|c|}{15 dias } & \multicolumn{3}{|c|}{23 dias } \\
\hline Fotoperíodo & $52,0 \mathrm{Aa}$ & $13,5 \mathrm{~B} \mathrm{a}$ & $50,5 \mathrm{Aa}$ & $53,0 \mathrm{Aa}$ & $20,0 \mathrm{Ba}$ & $56,0 \mathrm{Aa}$ \\
\hline $\begin{array}{l}\text { Escuro prévio } \\
\text { por } 15 \text { dias }\end{array}$ & $40,0 \mathrm{Ba}$ & $5,0 \mathrm{Cb}$ & $62,5 \mathrm{Aa}$ & $42,5 \mathrm{Ba}$ & $7,5 \mathrm{Cb}$ & $63,5 \mathrm{Aa}$ \\
\hline $\mathrm{CV}(\%)$ & \multicolumn{3}{|c|}{12,16} & \multicolumn{3}{|c|}{14,09} \\
\hline
\end{tabular}

\footnotetext{
${ }^{1}$ em sala de laboratório (variações diárias de temperatura entre 20 e $29^{\circ} \mathrm{C}$ ). Médias seguidas de mesma letra, minúscula na coluna e maiúscula na linha, não diferem entre si pelo teste de Scott-Knott a $5 \%$ de probabilidade.
} 
como na ausência de luz (Labouriau, 1983; Andrade, 1995). Possivelmente Ruta graveolens e outras como Foeniculum vulgare (Stefanello et al., 2006a) e Salvia splendens (Menezes et al., 2004) apresentama forma de fitocromo fiA, que controla a germinação das sementes através da resposta de fluência muito baixa (Takaki, 2001).

A condição de alternância de temperatura obtida em condições de laboratório, resultou em alta germinabilidade de sementes de Ruta graveolens. Essa variação de temperatura age sobre o tegumento da semente, deixando-o mais permeávelà água e ao oxigênio, podendo interferir diretamente sobre substâncias promotoras e inibidoras da germinação (Carvalho \& Nakagawa, 2000). Segundo Copeland \& McDonald (1995), algumas espécies apresentam melhor comportamento germinativo nessas condições, pois alternâncias de temperatura correspondem às flutuações naturais do ambiente.

$\mathrm{A} 30^{\circ} \mathrm{C}$, as sementes apresentaram baixos percentuais de germinação tanto quando estas receberam estimulo luminoso ou não, indicando que a temperatura foi prejudicial para essa espécie. Da mesma forma, Silva \& Aguiar (1998) e Pinheiro \& Borghetti (2003) observaram maiores percentuais germinativos para Euterpe edulis, Ocotea catharinenses e Streptocalyx floribundus a $25^{\circ} \mathrm{C}$, respectivamente. Embora a alta temperatura não tenha impedido o processo germinativo, verificou-se uma redução significativa na percentagem de germinação tanto comestimulo luminoso $(20 \%)$ como na ausência de luz nos primeiros 15 dias $(7,5 \%)$, sugerindo que esta temperatura esteja próxima do limite máximo de tolerância da espécie.
TABELA2. Porcentagem de germinação de sementes de Ruta graveolens, emfunção do potencial osmótico da solução de manitol. Alta Floresta-MT, 2008

\begin{tabular}{|c|c|c|}
\hline \multirow{2}{*}{$\begin{array}{l}\text { Potencial osmótico } \\
\text { (MPa) }\end{array}$} & \multicolumn{2}{|c|}{ Germinaçāo acumulada } \\
\hline & $\begin{array}{l}\text { Dados } \\
\text { originais (\%) }\end{array}$ & $\begin{array}{c}\text { Dados } \\
\text { transformados }\end{array}$ \\
\hline 0,0 & 55,0 & $7,43 \mathrm{a}$ \\
\hline$-0,2$ & 43,5 & $6,63 \mathrm{ab}$ \\
\hline$-0,4$ & 29,0 & 5,40 bc \\
\hline$-0,6$ & 24,0 & $4,91 \quad c$ \\
\hline$-0,8$ & 17,0 & 4,18 \\
\hline$-1,0$ & 8,0 & 2,82 \\
\hline $\mathrm{CV}$ & & \\
\hline
\end{tabular}

Médias seguidas de mesma letra nas colunas não diferem entre si pelo teste de Tukey a $5 \%$ de probabilidade. ${ }^{1}$ Dados transformados em raiz quadrada de $(x+0,5)$.

\section{Restrição hídrica}

$\mathrm{Na}$ Tabela 2 estão apresentados os dados da porcentagem de germinação das sementes de Ruta graveolens em função do potencial osmótico da solução de manitol.

Reduções significativas nas porcentagens de germinação foram observadas a partir de -0,4MPa. Nessa concentração, a redução na germinação foi da ordem de $47 \%$ em relação à testemunha. $A$ intensidade da resposta germinativa à restrição hídrica é variável entre as espécies, podendo reduzir tanto a porcentagem quanto a velocidade de germinação, havendo espécies muito sensíveis e outras mais

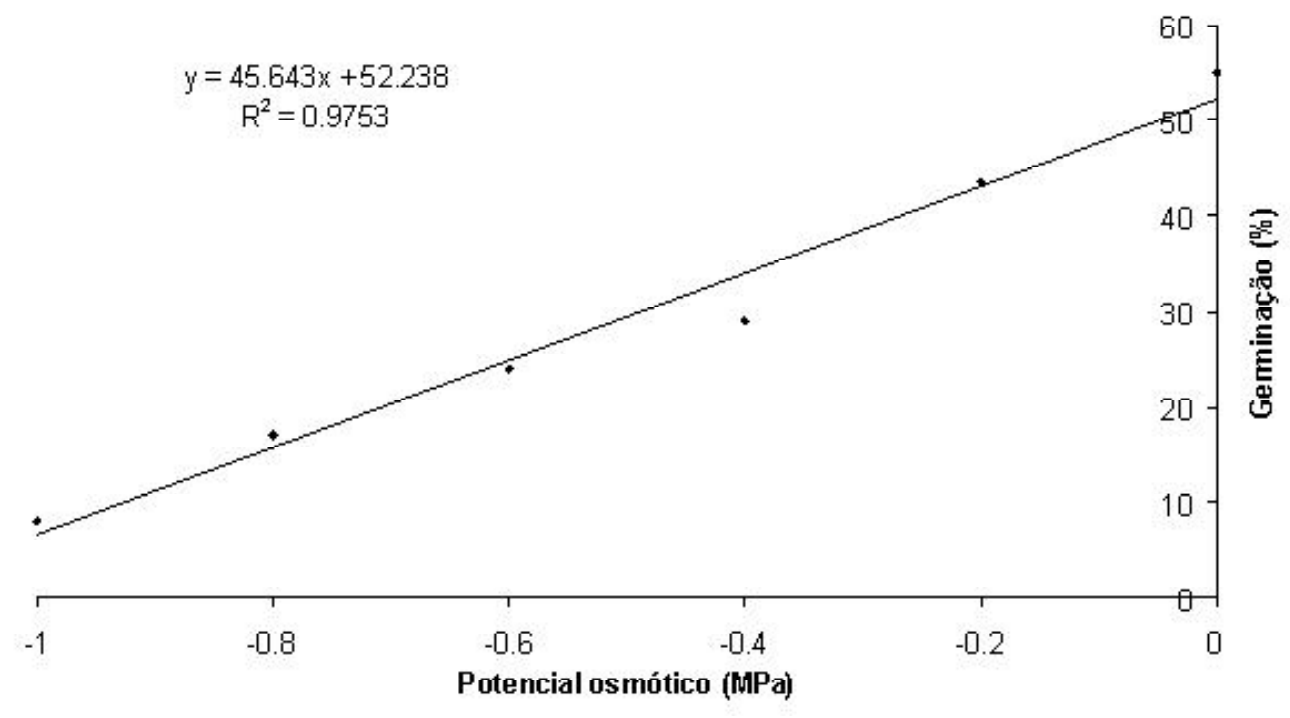

FIGURA 2. Efeito do potencial osmótico de soluções de manitol na germinação de sementes de Ruta graveolens. Alta Floresta-MT, 2008. 
resistentes (Bewley \& Black, 1994). Ruta graveolens comportou-se de forma sensível à restrição hídrica, assemelhando-se aos resultados obtidos por Stefanello et al. (2006b) em sementes de Pimpinella anisum e por Choinski \& Tuohy (1991) em sementes de Acacia sp.

A equação de regressão referente à germinação final de sementes de Ruta graveolens conduzidas sob diferentes potenciais osmóticos é apresentada na Figura 2. À medida que o potencial osmótico diminuiu, houve redução da porcentagem total de germinação e essa tendência seguiu modelo de regressão linear $(y=45,643 x+52,238)$, com coeficiente de determinação de 0,9753 .

A restrição hídrica provoca a redução na velocidade dos processos metabólicos e bioquímicos, atrasando ou interferindo diretamente no processo germinativo das sementes (Bradford, 1990), promovendo o aumento da concentração de solutos, alteração do pH da solução intracelulare aceleração das reações degenerativas da semente (Sun \& Leopold, 1997). Essa resposta pode ser atribuída à permeabilidade do tegumento da semente dessa espécie à solutos como o manitol, que apresenta baixo peso molecular, permitindo a entrada na semente, provocando o efeito de seca causado por esta solução (Tambelini \& Perez, 1998).

\section{Estresse Salino}

Os dados referente à germinação de sementes de Ruta graveolens submetidas a soluções de $\mathrm{NaCl}$ com diferentes potenciais osmóticos encontram-se na Tabela 3.

Houve redução da porcentagem de germinação à medida que aumentou a concentração
TABELA3. Porcentagemde germinação de sementes de Ruta graveolens, emfunção do potencial osmótico da solução de $\mathrm{NaCl}$. Alta Floresta-MT, 2008

\begin{tabular}{ccc}
\hline \multirow{2}{*}{$\begin{array}{c}\text { Potencial osmótico } \\
\text { (MPa) }\end{array}$} & \multicolumn{2}{c}{ Geminação acumulada } \\
\cline { 2 - 4 } & $\begin{array}{c}\text { Dados } \\
\text { originais (\%) }\end{array}$ & $\begin{array}{c}\text { Dados } \\
\text { transformados }\end{array}$ \\
\hline 0,0 & 61,5 & $7,84 \mathrm{a}$ \\
$-0,2$ & 51,0 & $7,14 \mathrm{ab}$ \\
$-0,4$ & 48,5 & $6,97 \mathrm{ab}$ \\
$-0,6$ & 45,5 & $6,71 \mathrm{ab}$ \\
$-0,8$ & 31,5 & $5,63 \mathrm{bc}$ \\
$-1,0$ & 22,0 & $4,70 \quad \mathrm{c}$ \\
\hline CV & \multicolumn{3}{c}{$12,48 \%$} & & \\
\hline
\end{tabular}

Médias seguidas de mesma letra nas colunas não diferem entre si pelo teste de Tukey a $5 \%$ de probabilidade. ${ }^{1}$ Dados transformados em raiz quadrada de $(x+0,5)$.

de $\mathrm{NaCl}$, no entanto, reduções significativas foram observadas apenas a partir de $-0,8 \mathrm{MPa}$. O menor valor de porcentagem de germinação foi encontrado no potencial osmótico $-1,0 \mathrm{MPa}(22 \%)$.

Resultados semelhantes foram encontrados com outras espécies como Copaifera langsdorffii (Jeller \& Perez, 1995), Bauhinia forficata (Fanti \& Perez, 1996), Campsis radicans (Chachalis \& Reddy, 2000) e Ambrosia artemisifolia (DiTommaso, 2004), cujo limite de tolerância variou entre $-0,4$ e $-0,8 \mathrm{MPa}$.

A presença excessiva de sais como $\mathrm{NaCl}$ na solução pode provocar redução do potencial hídrico do solo, induzindo a menor capacidade de absorção de água pelas sementes (Fanti \& Perez, 1998).

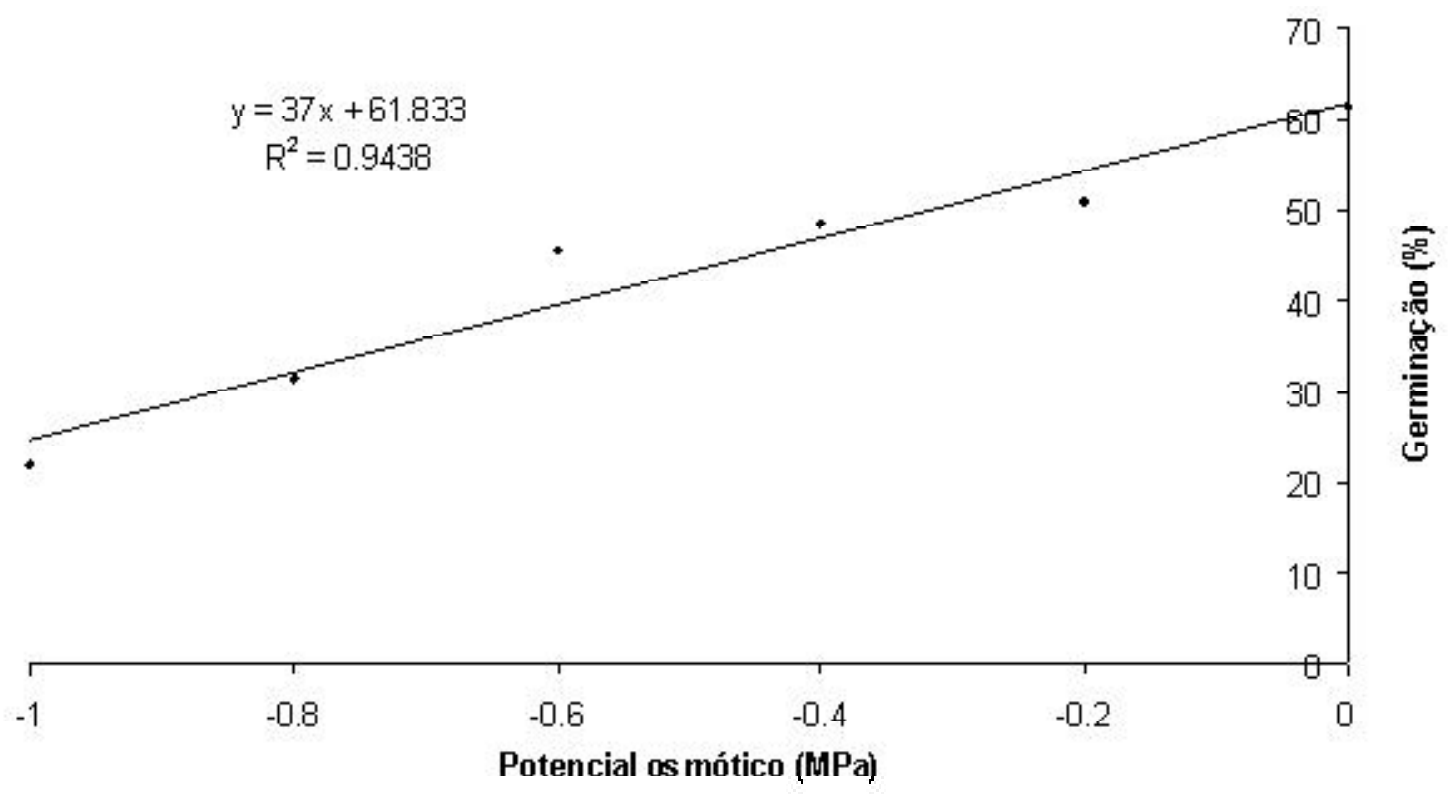

FIGURA 3. Efeito do potencial osmótico de soluções de $\mathrm{NaCl}$ na germinação de sementes de Ruta graveolens. Alta Floresta-MT, 2008. 
A Figura 3 apresenta a equação de regressão para a germinação final de sementes de Ruta graveolens sob soluções salinas com crescentes potenciais osmóticos. À medida que o potencial osmótico diminuiu, houve redução da porcentagem total de germinação seguindo uma tendência de regressão linear $(y=37 x+1,833)$, com coeficiente de determinação de 0,9438 .

\section{Textura do substrato e profundidade de semeadura}

$\mathrm{Na}$ Tabela 4, estão apresentadas a porcentagem de emergência de plântulas de Ruta graveolens, em função da textura do substrato e profundidade de semeadura.

Não houve diferença entre os substratos estudados. Apenas o fator profundidade influenciou significativamente no número de plântulas emersas, sendo observado menor número destas à medida que a profundidade era aumentada. A $4 \mathrm{~cm}$, não foi observada emergência de plântula.

Maiores percentuais de emergência ocorreram a $0 \mathrm{~cm}$, sendo que para areia, não houve diferença significativa entre 0 e $0,5 \mathrm{~cm}$. Entretanto, a emergência de plântulas foi semelhante para as profundidades de 0,5 e $1 \mathrm{~cm}$ para areia e mistura entre terra e areia. Quando foi utilizada apenas terra, apesar da diferença significativa coma semeadura realizada na superfície, a emergência das plântulas foi semelhante entre 0,5 e $2 \mathrm{~cm}$. Esses resultados assemelham-se aos obtidos por Guimarães et al. (2002) e Canossa et al. (2007), cuja emergência de Tridax procumbens e Alternanthera tenella, respectivamente, foi maior para as sementes colocadas a $0 \mathrm{~cm}$, diminuindo nas profundidades de 1 a $3 \mathrm{~cm}$, e se tornado nulas para profundidades iguais ou superiores a $4 \mathrm{~cm}$.

TABELA 4. Porcentagem de emergência de plântulas de Ruta graveolens, em função da profundidade de semeadura e textura do substrato. Alta Floresta-MT, 2008

\begin{tabular}{crrr}
\hline \multirow{2}{*}{$\begin{array}{c}\text { Profundidade } \\
(\mathbf{c m})\end{array}$} & \multicolumn{3}{c}{ Textura do substrato } \\
\cline { 2 - 4 } & \multicolumn{1}{c}{ Arela } & Terra:Arela & \multicolumn{1}{c}{ Terra } \\
\hline $\mathbf{0 , 0}$ & $36 \mathrm{Aa}$ & $44 \mathrm{Aa}$ & $42 \mathrm{Aa}$ \\
$\mathbf{0 , 5}$ & $28 \mathrm{ABa}$ & $17 \mathrm{Ba}$ & $18 \mathrm{Ba}$ \\
$\mathbf{1 , 0}$ & $16 \mathrm{BCa}$ & $10 \mathrm{BCa}$ & $10 \mathrm{Ba}$ \\
$\mathbf{2 , 0}$ & $8 \mathrm{Ca}$ & $4 \mathrm{CDa}$ & $7 \mathrm{Ba}$ \\
$\mathbf{4 , 0}$ & $0 \mathrm{Da}$ & $0 \mathrm{Da}$ & $0 \mathrm{Ca}$ \\
\hline $\mathbf{C V}$ & \multicolumn{3}{c}{$27,14 \%$} \\
\hline
\end{tabular}

Médias seguidas de mesma letra maiúscula nas colunas e minúscula nas linhas não diferem entre si pelo teste de Tukey a $5 \%$ de probabilidade.
As sementes posicionadas na superfície do solo apresentaram maior emergência de plântulas do que aquelas colocadas em maiores profundidades (Dias Filho, 1996). Aelevada emergência de plântulas de Ruta graveolens em superfície pode estar relacionada ao fato de que esta foi mantida em superfície, sempre úmida, evitando ressecamento, permitindo assim, o fornecimento de água em quantidade suficiente para ativação dos mecanismos que comandam o processo de germinação das sementes (Bewley \& Black, 1994).

Em maiores profundidades, mesmo em condições adequadas de umidade no substrato, a germinação da semente pode ser afetada pela reduzida disponibilidade de oxigênio e altos níveis de $\mathrm{CO}_{2}$. Além disso, a menor emergência de plântulas pode estar associada à barreira física imposta pelo solo à germinação (limitação física da expansão do embrião) (Toledo et al., 1993; Canossa et al., 2007).

O substrato corresponde ao meio onde a semente é colocada para germinar, e tem a função de manter as condições adequadas para a germinação da mesma (Dousseau et al., 2008), este deve dar condições adequadas de estrutura, aeração e capacidade de retenção de água para a boa emergência de plântulas (Figlioglia et al., 1993). Entretanto, deve-se ressaltar que, mesmo optandose por um substrato que apresente características adequadas para a manutenção das condições de germinabilidade das sementes, se estas forem colocadas em profundidades superiores a $0,5 \mathrm{~cm}$, a quantidade de plântulas será reduzida drasticamente, como observado no presente trabalho.

Dessa maneira, pode-se concluir que nas condições experimentais, sementes de Ruta graveolens são indiferentes à luz, germinando melhor em temperatura constante de $25^{\circ} \mathrm{C}$ ou alterna (20$30^{\circ} \mathrm{C}$ ). Potenciais osmóticos a partir de $-0,4 \mathrm{MPa}$ influenciamnegativamente no processo germinativo. A partir de $-0,8 \mathrm{MPa}$ induzido por solução salina de $\mathrm{NaCl}$, há prejuízo na germinação da espécie. Maiores percentuais de plântulas são obtidos quando a espécie é semeada na superfície do substrato.

\section{REFERÊNCIA}

ANDRADE, A.C.S. Efeito da luz e da temperatura na germinação de Leandra breviflora Cogn., Tibouchina benthamiana Cogn., Tibouchina grandifolia Cogn. e Tibouchina morincadiana (DC.) Baill. (Melastomataceae). Revista Brasileira de Sementes, v.17, n.1, p.29-35, 1995. BEWLEY, J.D.; BLACK, M. Seeds: physiology of development and germination. 2.ed. New York: Plenum, 1994. 445p.

BRADFORD, K.J.A. Water relations analysis of seed germination rates. Plant Physiology, v.94, n.3, p.840-9, 1990. 
BRASIL. Ministério da Agricultura e Reforma Agrária. Regras para análise de sementes. Brasília: SNDA/ DNDV/CLAV, 1992. 365p.

CANOSSA, R.S. et al. Profundidade de semeadura afetando a emergência de plântulas de Alternanthera tenela. Planta Daninha, v. 25, n.4, p.719-25, 2007.

CARVALHO, N.M.; NAKAGAWA, J. Sementes: ciência, tecnologia e produção. 4.ed. Jaboticabal: Funep, 2000. $588 p$.

CHACHALIS, D.; REDDY, K.N. Factors affeting Campsis radicans seed germination and seedling emergence. Weed Science, v.48, p.212-6, 2000.

CHOINSKI, J.S.; TUOHY, J.M. Effect of water potential and temperature on the germination of four species of African savanna trees. Annals of Botany, n.68, p.227-33, 1991. COPELAND, L.O.; McDONALD, M.B. Principles of seed science and technology. New York: Chapman \& Hall, 1995. 409p.

DIAS FILHO, M.B. Germination and emergence of Stachytarphela cayennes and Ipomea asarifolia. Planta Daninha, v.14, n.2, p.118-26, 1996.

DiTOMMASO, A. Germination behavior of common ragweed (Ambrosia artemisifolia) populations across a range of salinities. Weed Science, v.52, p.1002-9, 2004. DOUSSEAU, S. et al. Germinação de sementes de tanchagem (Plantago tomentosa Lam.): influência da temperatura, luz e substrato. Ciência e Agrotecnologia, v.32, n.2, p.438-43, 2008

FANTI, S.C.;PEREZ, S.C.J.G.A. Efeito do estresse hídrico, salino e térmico no processo germinativo de sementes de Andenanthera pavonina. Revista Brasileira de Sementes, v.20, n.1, p.167-77, 1998.

FANTI, S.C.; PEREZ, S.C.J.G.A. Efeitos doestresse hídrico e salino na germinação de Bauhinia forficata Link. Revista Ceres, v.43, n.249, p.654-62, 1996.

FERREIRA, D.F. Sisvar Versão 4.3. Lavras:UFLA, 2003. (Suporte técnico CAPES/CNPq).

FIGLIOLIA, M.B.; OLIVEIRA, E.C.; PIÑA-RODRIGUES, F.C.M. Análise de sementes. In: AGUIAR, I.B.; PIÑARODRIGUES, F.C.M. (Eds.). Sementes florestais tropicais. Brasília:ABRATES, 1993. p.137-74.

GUIMARAES, S.C.; SOUZA, I.F.; PINHO, E.V.R.V. Emergência de Tridax procumbens, em função da profundidade de semeadura, do conteúdo de argila no substrato e da incidência de luz na semente. Planta Daninha, v.20, n.3, p.413-9, 2002.

JELLER, H.;PEREZ, S.C.J.G.A. Efeito da salinidade e da semeadura em diferentes profundidades na viabilidade e no vigor de Copaifera langsdorffii Desf. Caesalpiniaceae. Revista Brasileira de Sementes, v.19, n.2, p.219-25, 1997.

LABOURIAU, L.G. A germinação das sementes Washington: Secretaria da O.E.A., 1983. 173p. LORENZI, H.; MATOS, F.J.A. Plantas medicinais do Brasil: nativas e exóticas. Nova Odessa: Instituto
Plantarum, 2002. 512p.

MAGUIRE, J.D. Speed of germination-aid in relation evaluation for seedling emergence vigor. Crop Science, v.2, n.2, p.176-77, 1962

MARCOS FILHO, J. Germinação de sementes. In: CICERO, S.M.; MARCOS FILHO, J.; SILVA, W.R. (Eds.). Atualização em produção de sementes. Campinas: Fundação Cargill, 1986. p.11-39.

MARTINS, M.R. et al. Plantas medicinais. Viçosa: UFV, 2003. 220p.

MENEZES, N.L. et al. Germinação de sementes de Salvia splendens Sellow em diferentes temperaturas e qualidades de luz. Revista Brasileira de Sementes, v.26, n.1, p.32-7, 2004

NASSIF, S.M.L.; PEREZ, S.C.J.G.A. Germinação de sementes de amendoim-do-campo (Pterogyne nitens Tul. - Fabaceae-Caesalpinoideae) submetidas a diferentes condições de estresse hídrico e salino. Revista Brasileira de Sementes, v.19, n.2, p.142-9, 1997. PEREZ, S.C.J.G.A.; TAMBELINI, M. Efeitos dos estresses salino e hídrico e do envelhecimento precoce na germinação de algarobeira. Pesquisa Agropecuária Brasileira, v.30, n.11, p.1289-95, 1995.

PINHEIRO, F.; BORGHETTI, F. Light and temperature requirements for germination of seeds of Aechmea nudicaulis (L.) Griesebach and Streptocalyx floribundus (Martius Ex Schultes f.) Mez (Bromeliaceae). Acta Botanica Brasílica, v.17, n.1, p.27-35, 2003.

SILVA, A.; AGUIAR, I.B. Germinação de sementes de canela-preta (Ocotea catharinenses) sob diferentes condições de luz e temperatura. Revista do Instituto Florestal, v.10, n.1, p.17-22. 1998.

SOUZA,O.I. et al. Atividades farmacológicas da arruda (Ruta graveolens). In: CONGRESSO DE ECOLOGIA DO BRASIL, 8., 2007, Caxambu. Anais ... São Paulo: Sociedade de Ecologia do Brasil, 2007. CD.

STEFANELLO, R. et al. Efeito da luz, temperatura e estresse hídrico no potencial fisiológico de sementes de funcho. Revista Brasileira de Sementes, v.28, n.2, p.135-41, 2006a.

STEFANELLO, R. et al. Influência da luz, temperatura e estresse hídrico na germinação e no vigor de sementes de anis. Revista Brasileira de Agrociência, v.12, n.1, p.45-50, 2006b.

SUN, W.Q.; LEOPOLD, A.C. Cytoplasmic vitrification and survival of anhydrobiotic organisms. Comparative Biochemistry and Physiology, v.117A, n.3, p.327-33, 1997.

TAMBELINI, M.; PEREZ, S.C.J.G. Efeitos do estresse hídrico simulado com PEG (6000) ou manitol na geminação de sementes de barbatimão (Stryphnodendron polyphyllum Mart.). Revista Brasileira de Sementes, v.20, n.1, p.226-32, 1998 .

TAKAKI, M. New proposal of classification of seeds based on forms of phytochrome instead of photoblastism. Revista Brasileira de Fisiologia Vegetal, v.13, n.1, p.1037, 2001.

TOLEDO, R.E.B.; KUVA, M.A.;ALVES, P.L.C.A.Fatores que afetam a germinação e a emergência de Xanthium strumarium L.: dormência, qualidade da luz e profundidade de semeadura. Planta Daninha, v.11, n.1/ 2, p.15-20, 1993 